\title{
Intrarenal resistance index for the assessment of acute renal injury in a rat liver transplantation model
}

\author{
Hai-Ying Kong ${ }^{1}$, Fen Chen ${ }^{2}$, Yong He ${ }^{2}$, Lin-Jiao Wu ${ }^{3}$, Li-Qing Wang ${ }^{1}$, Sheng-Mei Zhu' and Shu-Sen Zheng ${ }^{2 *}$
}

\begin{abstract}
Background: Acute kidney injury (AKI) is a common complication after liver transplantation (LT) and associated with a high mortality. The renal resistive index (RI) is used to assess early renal function impairment in critical care patients. However, limited data are available concerning changes of renal RI and the development of AKI early after reperfusion. We approached to investigate the changes of renal $\mathrm{RI}$ and AKI after reperfusion in a rat liver transplantation model.

Methods: Rats were randomly divided into sham group or LT group. Ten rats in each group were used for the hemodynamic study and twenty for Doppler measurements during the procedure. Ten rats were sacrificed 30 min or $2 \mathrm{~h}$ after the reperfusion. We harvested kidneys, serum and urine for further analysis of the renal function.

Results: The intrarenal Rl increased significantly in the anhepatic stage and decreased significantly after the reperfusion in the LT group compared with sham group $(P<0.05)$. AKI was seen after the reperfusion in the LT group. No correlation was noted between the RI and renal function parameters 30 min after reperfusion.

Conclusions: The intrarenal RI increased significantly during the anhepatic stage, and decreased significantly early after the reperfusion. Intrarenal RI was unable to assess renal function in a rat liver transplantation model.
\end{abstract}

Keywords: Liver transplantation, Doppler sonography, Renal function, Resistive index, Cys, NGAL

\section{Background}

AKI is one of the most common complications after LT, especially in the early postoperative period [1-6]. Although the precise cause of the renal injury after LT remains elusive and is likely multifactor [2,5,7-9], renal vascular tone is one of the factors closely related to the effective renal perfusion and subsequent renal function [10-12]. In many cases, such as hemorrhagic shock, immediate elevations in renal RI have been reported and renal injury may occur as a functional disorder secondary to splanchnic pooling of blood, reduced effective arterial volume and compensatory activation of vasopressor systems leading to increased renal vascular tone [13]. The pathophysiology of human liver transplantation was more complex than hemorrhage shock, and there would be acute changes in intraoperative

\footnotetext{
* Correspondence: shusenzheng@zju.edu.cn

${ }^{2}$ Key Lab of combined Multi-organ Transplantation, Ministry of Public Health, the First Affiliated Hospital, Zhejiang University School of Medicine, 79 Qingchun Road, Hangzhou 310003, PR China

Full list of author information is available at the end of the article
}

hemodynamics resulting from suprarenal inferior vena cava (IVC) occlusion, secondary to ischemia-reperfusion injury in the liver in the procedure [3,6], and would induce major changes in renal vascular tone. However, limited data related to renal vascular tone and renal function directly after reperfusion existed during LT [11,12].

The Doppler waveform analysis of the kidneys, semiquantified as the RI, has accumulated for both acute and chronic renal diseases $[11,12,14,15]$. It has also been thought to indirectly reflect the degree of resistance in the intrarenal vasculature [16] and is gaining growing attention as an important factor predicting the occurrence of AKI in critical care patients [14,17]. The patients with an elevated RI were at greater risk for development of AKI and overt hepatorenal syndrome [14]. Early identification of the renal vascular tone and development of AKI in this special patient population may be beneficial because clinical therapies may be modified to avoid other nephrotoxins and to improve against AKI. 
As serum Cystatin C(Cys), a more accurate predictive biomarker of glomerular filtration rate (GFR), and neutrophil gelatinase-associated lipocalin (NGAL), an early predictive biomarker of AKI, have been successfully used in the liver diseases and LT studies [4,6,18-22], we approached to investigate the changes of renal RI values during anhepatic stage and early neohepatic stage as well as the Cys, NGAL after reperfusion in a rat liver transplantation model. This investigation might generate new insights into the response of the kidney to potential harmful factors during the early reperfusion and raise the concern into the diagnostic value of RI measurements alone.

\section{Methods}

Animals

Male Sprague-Dawley rats, aged 8-10 wks, weighing 200-250 g, purchased from the Animal Resource Center at Zhejiang University School of Medicine, were used as donors and recipients. All the animal research protocols used in this study were approved by the Animal Ethics Review Committees of Zhejiang University and accorded with the principles stated in the Guide for the Care and Use of Laboratory Animals (National Institutes of Health publication, 1985).

\section{Experimental design and surgical procedure}

The rats were randomly divided into two groups: sham operation group (Sham group; $\mathrm{n}=50$ ) and orthotopic LT group (LT group; $n=50$ ). Ten recipients in each group were chosen for hemodynamic study; ten for examination of Doppler ultrasound during the anhepatic stage and ten for examination after the reperfusion; and $30 \mathrm{~min}$ or $2 \mathrm{~h}$ after the reperfusion, ten recipients were sacrificed, and blood and kidney samples were collected for further analysis.

Orthotopic liver syngenic graft transplantations were performed with the two-cuff technique, which was first established by Kamada [23]. The rats were intraperitoneally injected with chloral hydrate anesthesia, $200 \mathrm{mg} \cdot \mathrm{kg}^{-1}$ body weight or to effect. During the surgery, the rats were allowed to breathe oxygen on an electric heating pad under a warming light. The graft was stored in cold saline with a target cold ischemic time of $80 \mathrm{~min}$; More than $90 \%$ of the rats survived this surgery. To compensate for insensible water loss and fasting period, each animal was given lactated Ringer's $6 \mathrm{ml} / \mathrm{kg}$ per hour using a two-channel infusion pump (Anne; Abbott) during animal preparation and liver section. There was no administration of vasoconstrictors and calcinenrin inhibitor during the operation.

\section{Hemodynamic study}

Ten rats in each group were used for hemodynamic study. After induction of anesthesia, left cervical arteries were cannulated by a catheter for measurement of mean arterial pressure (MAP). The catheter was connected via the pressure transducer (YPJ01 Pressure Transducer, physiological experiment system, Chengdu Instruments, Sichuan, China) to a multichannel data-recording unit (RM6240C, physiological experiment system, Chengdu Instruments) for continuous pressure monitoring and recording. MAP and HR were recorded before removing the liver, at the time of clamping and after the reperfusion. All data were analyzed using the physiological experiment software system (RM6240 physiological experiment system, Chengdu Instruments).

\section{Doppler measurements}

Colour-coded duplex sonography was performed using an Esaote Mylab duplex device with a curved 2-5 MHz transducer following a standardized protocol [24]. Baseline Doppler ultrasound examinations (Esaote Mylab90, XVISION, IOE323, Italy) and calculation of RI were performed on the right kidney. Three consecutive measurements at segmental and arcuate renal arteries on the right kidney were averaged. RI values were calculated automatically by the ultrasound machine using standard methodology $(\mathrm{RI}=$ [peak systolic velocity-peak diastolic velocity]/peak systolic velocity). RI assessments were made $10 \mathrm{~min}, 15 \mathrm{~min}$ after clamping of the portal vein and IVC; $5 \mathrm{~min}, 10 \mathrm{~min}, 15 \mathrm{~min}, 20 \mathrm{~min}$, and $30 \mathrm{~min}$ after the reperfusion. RI assessments were also made at the above time points in the sham group. All Doppler examinations were done by one examiner (CF).

\section{Assessment of liver and renal function after reperfusion}

Blood samples were collected from the recipients $30 \mathrm{~min}$ and $2 \mathrm{~h}$ after the reperfusion (10 rats for sampling at each time point) and processed within $2 \mathrm{~h}$ after collection. Blood collected in serum separator tubes was allowed to clot for 15-20 $\mathrm{min}$ and then centrifuged for $12 \mathrm{~min}$ at $1000 \mathrm{~g}$. Serum was collected and subsequently frozen at $-20^{\circ} \mathrm{C}$ until further analysis: $50 \mu \mathrm{l}$ for the measurement of alanine aminotransferase (ALT), aspartate aminotransferase (AST), concentrations of $\mathrm{Na}^{+}$and serum creatinine activities, reported in units per liter (Hitachi 747 Automatic Analyzer; Boehringer Mannheim $\mathrm{GmbH}$, Mannheim, Germany); and $50 \mu \mathrm{l}$ for NGAL immunoassay. Quantitative NGAL levels were measured with a sandwich enzymelinked immunosorbent assay (R\&D Systems, Minneapolis, Minn., USA) according to the manufacturer's instructions. Concentrated samples were diluted up to 80-fold with the manufacturerprovided diluent. Standards, samples and controls were run in duplicate, and the resulting chromogen was read at $450 \mathrm{~nm}$ with an additional 570-nm wavelength correction (Tecan, San Jose, Calif., USA). NGAL concentrations (ng/ $\mathrm{ml}$ ) were then calculated on the basis of the constructed 
Table 1 Hemodynamic variables of the two groups during the different phases of liver transplantation

\begin{tabular}{|c|c|c|c|c|c|c|}
\hline Parameters & $\mathrm{BL}$ & $\mathrm{C5}$ & R5 & R15 & R30 & R120 \\
\hline \multicolumn{7}{|l|}{$\mathrm{MAP}(\mathrm{mmHg})$} \\
\hline Sham group & $80 \pm 6.3$ & $79 \pm 6$ & $82 \pm 6.4$ & $81 \pm 6.1$ & $80 \pm 6.2$ & $83 \pm 6$ \\
\hline LT group & $83 \pm 6.5$ & $54 \pm 4.8^{*}$ & $64 \pm 5.2^{*}$ & $66 \pm 5.5^{*}$ & $68 \pm 6.3^{*}$ & $76 \pm 7.1$ \\
\hline \multicolumn{7}{|l|}{$\mathrm{HR}(\mathrm{bpm})$} \\
\hline Sham group & $80 \pm 7.5$ & $82 \pm 9.3$ & $84 \pm 9.0$ & $82 \pm 8.1$ & $80 \pm 8.7$ & $81 \pm 9.5$ \\
\hline LT group & $81 \pm 6.3$ & $114 \pm 11.2^{*}$ & $98 \pm 10.6^{*}$ & $94 \pm 9.8^{*}$ & $90 \pm 8.5^{*}$ & $93 \pm 9.6^{*}$ \\
\hline
\end{tabular}

Values are expressed as mean \pm SD. $*$ : $P<0.05$, vs. sham group.

Sham: sham operating; LT: liver transplantation. BL: baseline; $C_{5}: 5$ min after portal vein clamping; $R_{5}, R_{15}, R_{30}, R_{120}: 5$ min, 15 min, 30 min, 120 min after reperfusion.

standard curves on respective enzyme-linked immunosorbent assay plates. Standard curve $\mathrm{R}^{2}$ values ranged from 0.9903 to 0.9987 . And another $50 \mu \mathrm{l}$ was used for Cys immunoassay. Quantitative Cys levels were measured with a sandwich enzymelinked immunosorbent assay (R\&D Systems, Minneapolis, Minn., USA) according to the manufacturer's instructions. Urine samples were collected during the reperfusion period, and the volume of urine produced was recorded. Urine concentrations of $\mathrm{Na}$ ${ }^{+}$and creatinine were measured (Vetlab Services) and the $\mathrm{FE}_{\mathrm{Na}}$ was calculated as [(urine sodium/ plasma sodium)/ (urine creatinine/plasma creatinine) $] \times 100$.

Table 2 Comparison of liver function and renal function $\mathbf{3 0} \mathrm{min}, \mathbf{2} \mathrm{h}$ after reperfusion in the two groups

\begin{tabular}{|c|c|c|}
\hline Parameters & $30 \mathrm{~min}$ & $2 \mathrm{~h}$ \\
\hline \multicolumn{3}{|l|}{$\mathrm{ALT}(\mathrm{U} / \mathrm{L})$} \\
\hline Sham group & $25.2 \pm 10.1$ & $26.1 \pm 9.8$ \\
\hline LT group & $317.56 \pm 106.24^{*}$ & $405 \pm 108.07^{*}$ \\
\hline \multicolumn{3}{|l|}{$\mathrm{AST}(\mathrm{U} / \mathrm{L})$} \\
\hline Sham group & $45.6 \pm 10.4$ & $47.2 \pm 9.8$ \\
\hline LT group & $412 \pm 109.12^{*}$ & $846.13 \pm 213.51^{*}$ \\
\hline \multicolumn{3}{|l|}{$\mathrm{sCr}(\mathrm{mg} / \mathrm{dL})$} \\
\hline Sham group & $7.4 \pm 2.3$ & $8.2 \pm 2.5$ \\
\hline LT group & $36.1 \pm 13.2^{*}$ & $34.7 \pm 11.2^{*}$ \\
\hline \multicolumn{3}{|l|}{$\mathrm{NGAL}(\mathrm{mg} / \mathrm{L})$} \\
\hline Sham group & $0.83 \pm 0.11$ & $0.91 \pm 0.15$ \\
\hline LT group & $1.53 \pm 0.37^{*}$ & $1.72 \pm 0.39^{*}$ \\
\hline \multicolumn{3}{|l|}{ Cys(mg/L) } \\
\hline Sham group & $0.11 \pm 0.03$ & $0.14 \pm 0.02$ \\
\hline LT group & $1.32 \pm 0.33^{*}$ & $1.18 \pm 0.46^{*}$ \\
\hline \multicolumn{3}{|l|}{$\mathrm{FE}_{\mathrm{Na}}(\%)$} \\
\hline Sham group & $0.28 \pm 0.04$ & $0.31 \pm 0.05$ \\
\hline LT group & $1.22 \pm 0.14^{*}$ & $1.28 \pm 0.12^{*}$ \\
\hline
\end{tabular}

Values are expressed as mean \pm SD. ${ }^{*}: P<0.05$, vs. sham group. Sham: sham operating; LT: liver transplantation.

\section{Histology and Quantification of Renal Injury}

The kidney sections were stained with hematoxylin-eosin and periodic-acid Schiff. Samples were analyzed for tubular cell necrosis, tubular dilation, intratubular detachment $(\times 20)$, and evaluated in a blinded manner by a nephrologist. Abnormalities were graded by a semiquantitative score $\left(0\right.$ to $\left.4^{+}\right): 0$, no abnormalities; $1^{+}$, changes affecting $<25 \%$ of the tubules; $2^{+}, 25 \%$ to $50 \% ; 3^{+}, 50 \%$ to $75 \%$; $4^{+}$, $>75 \%$.

\section{Statistical analysis}

All data were presented as mean \pm standard deviations (SD), and statistical analyses were performed using SAS release 6.12 (SAS Institute, Cary, NC). Data between experimental groups were compared using a 2-tailed unpaired $t$ test. Correlation of RI values,Cys and NGAL was tested by linear regression. Significance was defined as $\mathrm{P}<0.05$.

\section{Results}

Hemodynamic changed during liver transplantation In the LT group, MAP decreased slightly while HR increased significantly during the anhepatic stage. After a compensatory increase of MAP and decrease of HR during the initial reperfusion stage, the MAP, HR changed gradually toward the value recorded at baseline after the reperfusion in the LT recipients (Table 1). In the sham group, the MAP and HR are stable during the operation.

\section{Renal resistive index and arterial velocity}

Renal resistive index and arterial velocity changed significantly during the procedure (Figure 1 ). The right intrarenal RI values increased significantly $10 \mathrm{~min}, 15 \mathrm{~min}$ after clamping IVC and portal vein, but decreased significantly $5 \mathrm{~min}, 10 \mathrm{~min}, 15 \mathrm{~min}, 20 \mathrm{~min}$ after reperfusion compared with sham group (Figure 1); The median peak arterial velocity increased significantly in the anhepatic stage and decreased significantly after the reperfusion compared with sham group (Figure 1). 

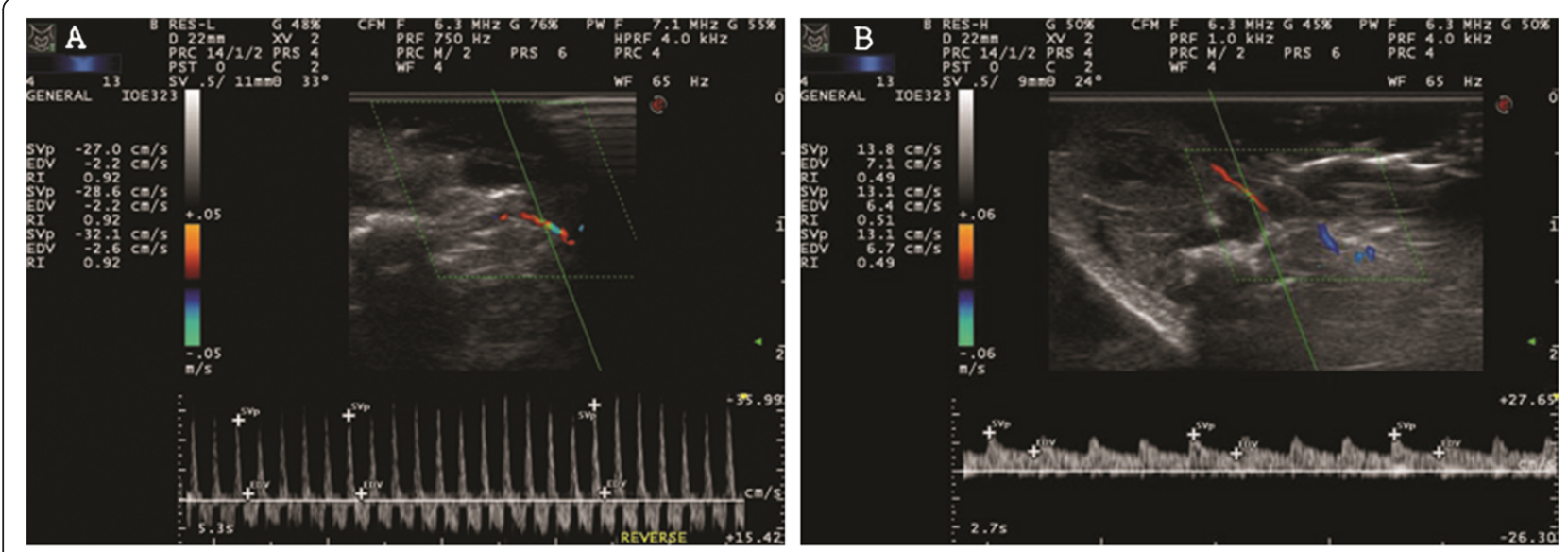

C

D
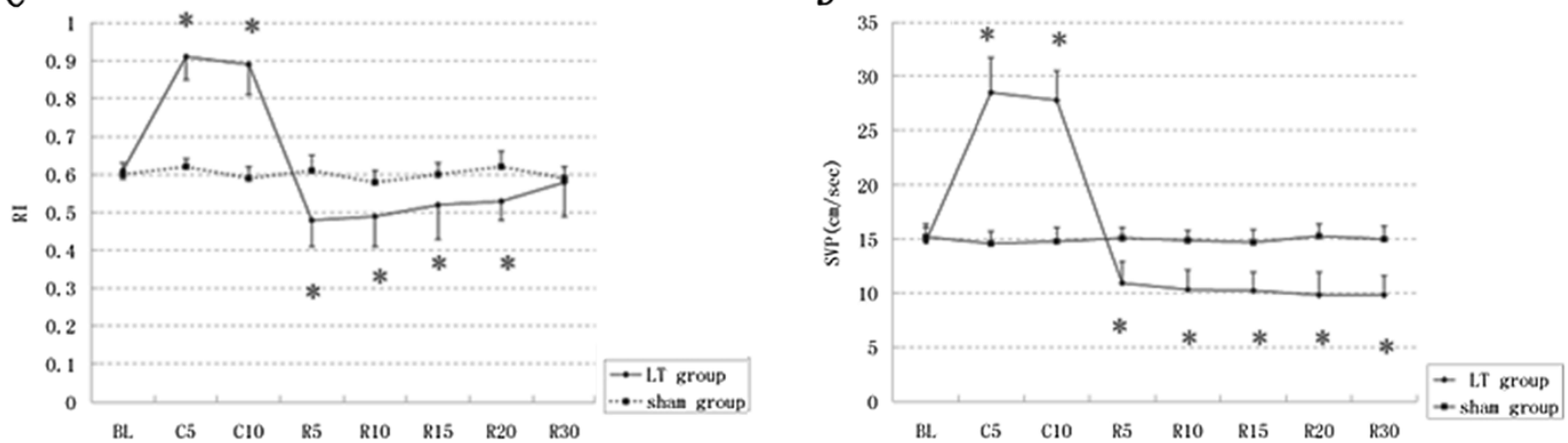

Figure 1 The right intrarenal RI recorded $10 \mathrm{~min}$ after portal vein and IVC clamping (A); The right intrarenal RI recorded 10 min after reperfusion in the recipient in the LT group (B). Renal RI recorded in the anhepatic stage and early after reperfusion (C); arterial velocity recorded in the anhepatic stage and early after reperfusion (D). Results are expressed as mean $\pm S D$. ${ }^{*}: P<0.05$, vs. sham group. $B L$ : baseline; $C_{5}$ : 5 min after portal vein clamping, $C_{10}$ : 10 min after portal vein and IVC clamping; $R_{5}, R_{10}, R_{15}, R_{20}, R_{30}: 5$ min, 10 min, 15 min, 20 min, 30 min after reperfusion; SVP: peak arterial systolic velocity.

Liver function and Renal function after the reperfusion The ALT and AST $30 \mathrm{~min}$ and $2 \mathrm{~h}$ after the reperfusion (Table 2 ) were significantly increased compared with sham group $(P<0.05)$. We measured plasma creatinine, Cys, NGAL $30 \mathrm{~min}$ and $2 \mathrm{~h}$ after the reperfusion. The serum levels of the three markers were increased $30 \mathrm{~min}, 2 \mathrm{~h}$ after the reperfusion significantly compared with sham group (Table 2). To better describe the behavior of diuresis and fractional sodium excretion, we also measured $\mathrm{FE}_{\mathrm{Na}} 30 \mathrm{~min}, 2 \mathrm{~h}$ after the reperfusion. The $\mathrm{FE}_{\mathrm{Na}}$ increased significantly compared with sham group (Table 2). There was no significant correlation between the RI and renal function parameters (sCr, Cys, NGAL) $30 \mathrm{~min}$ after the reperfusion $(\mathrm{P}>0.05)$.

\section{Renal Histology}

In the renal sections, we demonstrated multifocal acute tubular injury as evidenced by loss of brush border, flattening and loss of tubular epithelium, hyaline casts, medullary congestion, and hemorrhage. The tubular injury in the LT group was presented while the renal morphology of sham rats was near normal (Figure 2).

\section{Discussion}

LT patients run the risk of developing AKI and subsequent chronic kidney disease, affecting morbidity and mortality [1-3]. Ischemia is the most common cause of AKI; ischemic-induced renal tissue hypoxia is thought to be a major component in the development of AKI in promoting the initial tubular damage [25]. Ensuring the adequate perfusion and oxygenation of the kidney is central in the prevention of AKI [13].

Colour coded duplex sonography is the accepted method to assess kidney perfusion after transplantation $[12,17,24,26]$. A widely used Doppler parameter is the intrarenal RI. A better knowledge of the changes and diagnostic value of the intrarenal RI during the procedure will assist in designing studies to prevent AKI. 


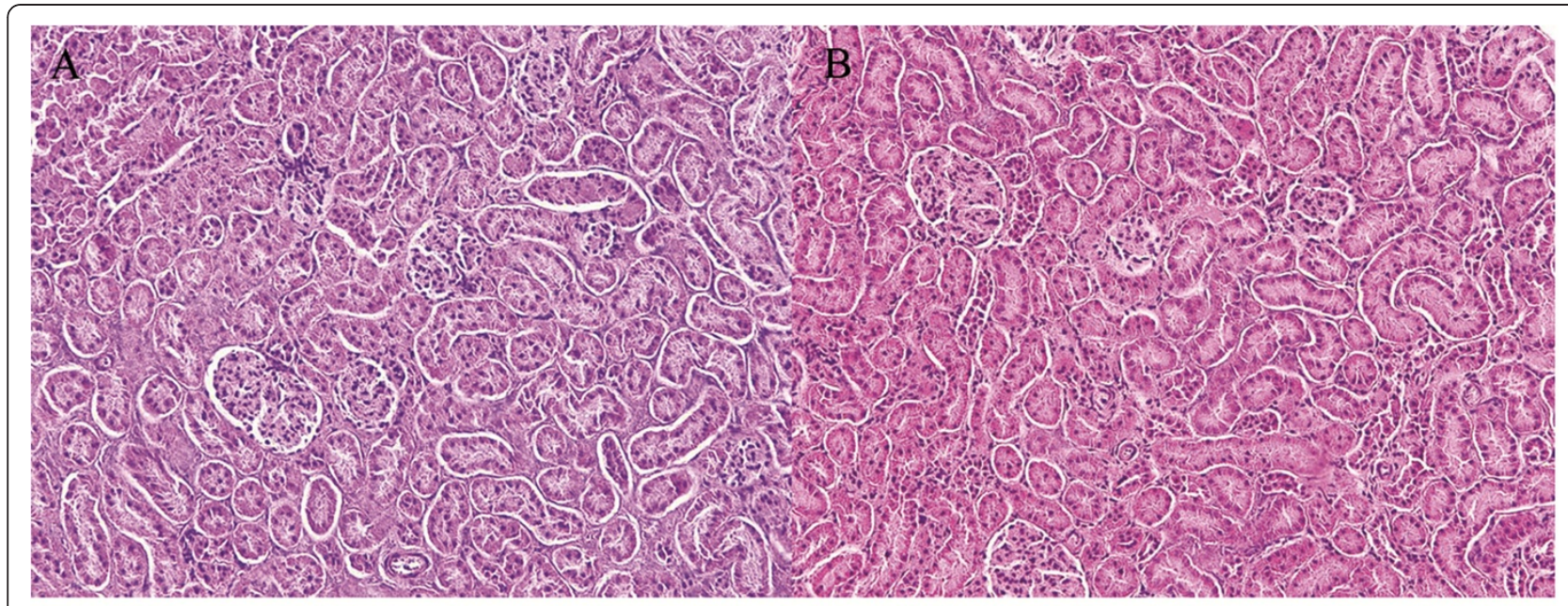

C

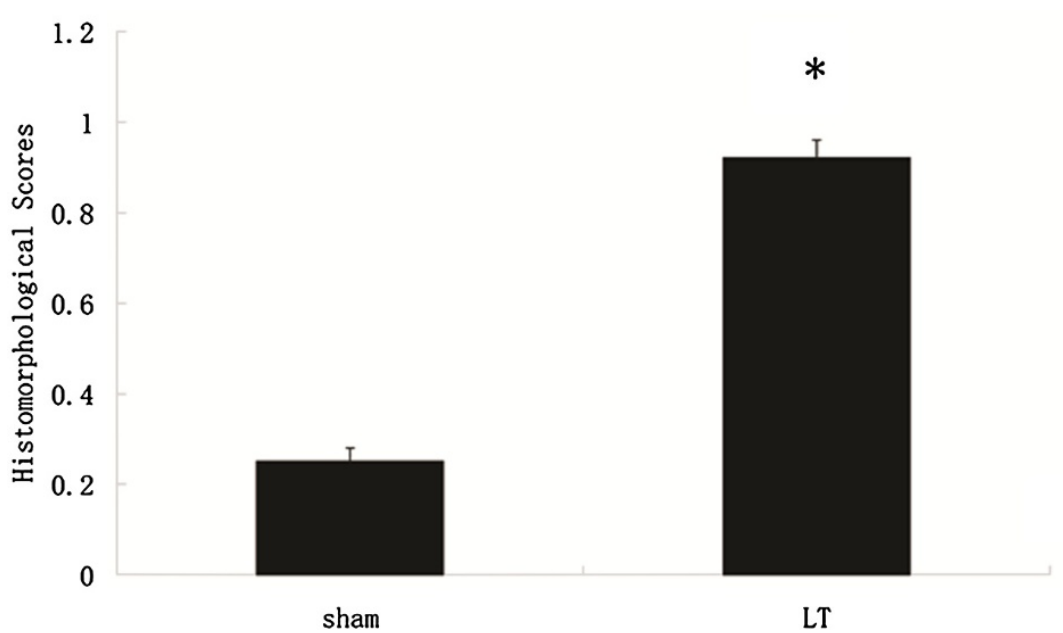

Figure 2 Histological evaluation of renal tissue obtained $\mathbf{2} \mathbf{~}$ after reperfusion. A hemotoxylin-eosin stain of kidney sections in the two groups(A- sham group, B- LT group); (C) Semiquantitative scoring of histological injury $(n=10)$. Data are expressed as the mean $\pm S D *$ * $P<0.05$, vs. sham group. Magnification: 20X.

This study provided information on the physiology of renal blood flow during the LT. The most striking findings were the increased renal RI in the anhepatic stage and decreased renal RI early after the reperfusion in a rat liver transplantation model. These results were different from the reports from Platt [26] and Pompili [12], which showed that the increased RI before LT can revert to normal a week after transplantation. RI measured at the different points can partially explain this apparent discrepancy, the RI values were initially measured on the first day after the operation but not immediately after the reperfusion, and the renal vasoconstriction due to the administration of cyclosponine (CSA) after operation can increase renal RI. The administration of CSA was associated with alterations in adrenergic tone and activation of the renin-angiotensin system [27].
The high renal RI values and arterial velocities in the anhepatic stage may be due to the acute changes in intraoperative hemodynamics secondary to the clamping of the vena cava. Clamping of the vena cava can result in the decreased cardiac preload and subsequent pronounced reduction in blood pressure; it also can increase caval and renal vein pressures and subsequently decrease the renal perfusion pressure (mean arterial pressure minus renal vein pressure) [3]. The high RI values suggested that the renal response to acute changes in hemodynamics during the anhepatic stage is similar to that in hemorrhage shock, relative hypovolemia may result in vasoconstriction and increased vascular resistance [13]. Substantial maldistribution of blood flow to the kidney might be present during the anhepatic stage.

In contrast to the findings in the anhepatic stage, the pronounced reduction in RI values early after the 
reperfusion compared with baseline was a novel finding $[12,26]$. The factors influencing the RI include $H R$, arterial stenosis, vein thrombosis and renal edema [12]. In this study, HR 5 min after clamping the portal vein and IVC was increased compared with that recorded 5 min after the reperfusion, thus the effect of the HR on the RI can be neglected. Although the mechanical renal artery stenosis can't occur as no intervention involving renal artery in LT, an increased number of thrombotic or inflammatory can obstruct capillaries in the corticomedullary junction and influence the vascular resistance [28]. The increased MPO activity in the renal tissue, suggested the leukocyte activation and infiltration occurred in renal tissue during LT [29]. In addition, the elevated NGAL after the reperfusion suggested that acute renal tubular injury occurred after the reperfusion. Furthermore, renal edema can also develop due to secondary to ischemia-reperfusion injury and venous ischemia [28]. Hence, the renal RI was expected to elevate after the reperfusion due to the changes in the renal parenchyma.

Thus, the declined renal RI values early after the reperfusion might be ascribed to the reduction of tone within renal arterioles, resulting from the imbalance between vasoconstrictive and vasodilative factors. During LT, on the reperfusion of the implanted liver, the graft itself can release substances such as proinflammatory cytokines $[3,30,31]$ and nitric oxide [32], which can lead to the imbalance between vasoconstrictive and vasodilative factors and subsequently disturbance the adapt capacity of vascular resistance and renal vascular dilates $[31,33]$. Furthermore, this reduction of tone within renal might overwhelm the elevated renal RI values related to leukocyte activation and infiltration, renal tubular injury and renal edema.

Usually, reduced renal vascular tone would also imply increased renal blood flow and improve renal function $[12,17]$. However, the impaired renal function including decreased GFR and renal tubule injury was presented immediately after the reperfusion in this rat liver transplantation model. The increased Cys suggested that the GFR might decrease significantly after the reperfusion. We also showed marked renal tubule injury including increased NGAL and $\mathrm{FE}_{\mathrm{Na}}$. $\mathrm{FE}_{\mathrm{Na}}$ has been used in the diagnosis of acute renal failure (ARF) to distinguish between the two main causes of ARF, prerenal state and acute tubular necrosis (ATN) [34,35]. The activation of neurohumoral systems (angiotensin, endothelin, and catecholamines) induced by the hemodynamic changes in portal hypertention-induced arterial vascular underfilling in liver cirrhosis can increase sodium reabsorption [36], and result in $\mathrm{FE}_{\mathrm{Na}}<1 \%$. Our data showed that $\mathrm{FE}_{\mathrm{Na}}$ increased after the reperfusion and levels $>1 \%$, indicating the presence of ATN after the reperfusion. The histologic evidence of tubule injury seen in the rats after the reperfusion also suggested that rats suffered AKI after the reperfusion. Similar findings were also reported before $[29,37]$. Postreperfusion syndrome [8] and surgical technique [6] have been pointed as risk factors related to AKI after reperfusion. The activated inflammatory response was seen in the liver tissue as well as renal tissue after reperfusion [37]. The graft ischemia/reperfusion injury induced the infiltration of leukocytes and liver cell injury. Proinflammatory cytokines released from the reperfused liver graft can act on the kidney tissue. IL-6 and TNF-a will trigger leukocyte-endothelium interactions and microcirculatory dysfunction, and alter renal microvascular $\mathrm{O}_{2}$ distribution and promote organ damage [25,38]. In addition, the venous warm ischemia from suprarenal IVC occlusion can also activate inflammatory response in renal tissue and aggravate kidney injury [39]. Macrophage activation and neutrophilic infiltration appear to be exaggerated during venous occlusion and increase severity of renal injury [39]. Thus, the renal microcirculation might be finally affected after reperfusion and estimation of renal perfusion is significantly limited [40]. The finding that no correlation between the RI values and the $\mathrm{sCr}$ and Cys and NGAL levels after reperfusion might suggested that Doppler ultrasound of renal arteries is not helpful in diagnosing renal function impairment post-LT.

Our study has several limitations. We focused on the short-term changes of renal RI and renal function after reperfusion, some important factors related to RI and renal function in human LT are not included in our study. We did not use inotropic agents, vasoconstrictors, immunosuppressive anti-rejection drugs. Second, we did not measure the $\mathrm{FE}_{\mathrm{Na}}$ during the anhepatic phase because of the insufficient urinary volume for analysis. In addition, the operation was carried out between the rats with normal preoperative liver function, some patients with chronic liver failure have hepatorenal syndrome, increased RI and impaired renal function before the operation.

\section{Conclusion}

In conclusion, there were major changes in renal RI during operation in liver transplantation rat model. RI increased significantly in the anhepatic stage but decreased drastically after early reperfusion of graft compared with baseline. Intrarenal RI was unable to assess renal function in a rat liver transplantation model.

\section{Competing interests}

The authors declare that they have no competing interests.

\section{Authors' contributions}

$\mathrm{KHY}$ participated in the design of the study, performed the statistical analysis and drafted the manuscript. CF performed the Doppler examinations. HY carried out the liver transplantation rat model. WLJ carried out the immunoassays. WLQ collected data and analyzed data. ZSM contributed substantially to the writing of the manuscript. ZSS conceived of the study, and participated in its design and coordination and helped to draft the manuscript. All authors read and approved the final manuscript. 


\section{Acknowledgements}

This work was supported by National Natural Science Foundation of China (81100320).

\section{Author details}

'Department of Anesthesiology, the First Affiliated Hospital, Zhejiang University School of Medicine, Hangzhou 310003, PR China. ${ }^{2}$ Key Lab of combined Multi-organ Transplantation, Ministry of Public Health, the First Affiliated Hospital, Zhejiang University School of Medicine, 79 Qingchun Road, Hangzhou 310003, PR China. ${ }^{3}$ State Key Laboratory for Diagnosis and Treatment of Infectious Diseases; Key Laboratory of Infectious Diseases, Zhejiang Province; Department of Infectious Diseases, First Affiliated Hospital, Zhejiang University School of Medicine, Hangzhou 310003, PR China.

Received: 4 July 2012 Accepted: 26 February 2013 Published: 2 March 2013

\section{References}

1. Smith JO, Shiffman ML, Behnke M, Stravitz RT, Luketic VA, Sanyal AJ, Heuman DM, Fisher RA, Cotterell AH, Maluf DG, Posner MP, Sterling RK: Incidence of prolonged length of stay after orthotopic liver transplantation and its influence on outcomes. Liver Transp/ 2009, 15:273-279.

2. Barri YM, Sanchez EQ, Jennings LW, Melton LB, Hays S, Levy MF, Klintmalm GB: Acute kidney injury following liver transplantation: definition and outcome. Liver Transp/ 2009, 15:475-483.

3. Velidedeoglu E, Bloom RD, Crawford MD, Desai NM, Campos L, Abt PL, Markmann JW, Mange KC, Olthoff KM, Shaked A, Markmann JF: Early kidney dysfunction post liver transplantation predicts late chronic kidney disease. Transplantation 2004, 77:553-556

4. Wagener G, Minhaz M, Mattis FA, Kim M, Emond JC, Lee HT: Urinary neutrophil gelatinase-associated lipocalin as a marker of acute kidney injury after orthotopic liver transplantation. Nephrol Dial Transplant 2011, 26:1717-1723.

5. Saner FH, Cicinnati VR, Sotiropoulos G, Beckebaum S: Strategies to prevent or reduce acute and chronic kidney injury in liver transplantation. Liver Int 2012, 32:179-188.

6. Portal AJ, McPhail MJ, Bruce M, Coltart I, Slack A, Sherwood R, Heaton ND, Shawcross D, Wendon JA, Heneghan MA: Neutrophil gelatinaseassociated lipocalin predicts acute kidney injury in patients undergoing liver transplantation. Liver Transp/ 2010, 16:1257-1266.

7. Tinti F, Umbro I, Meçule A, Rossi M, Merli M, Nofroni I, Corradini SG, Poli L, Pugliese F, Ruberto F, Berloco PB, Mitterhofer AP: RIFLE criteria and hepatic function in the assessment of acute renal failure in liver transplantation. Transplant Proc 2010, 42:1233-1236.

8. Cabezuelo JB, Ramírez P, Ríos A, Acosta F, Torres D, Sansano T, Pons JA, Bru M, Montoya M, Bueno FS, Robles R, Parrilla P: Risk factors of acute renal failure after liver transplantation. Kidney Int 2006, 69:1073-1080.

9. Paugam-Burtz C, Kavafyan J, Merckx P, Dahmani S, Sommacale D, Ramsay $M$, Belghiti J, Mantz J: Postreperfusion syndrome during liver transplantation for cirrhosis: outcome and predictors. Liver Transpl 2009, 15:522-529.

10. Dewitte $A$, Coquin J, Meyssignac $B$, Joannès-Boyau O, Fleureau $C$, Roze $H$, Ripoche J, Janvier G, Combe C, Ouattara A: Doppler resistive index to reflect regulation of renal vascular tone during sepsis and acute kidney injury. Crit Care 2012, 16:R165.

11. Stell D, Downey D, Marotta P, Solano E, Khakhar A, Quan D, Ghent C, McAlister V, Wall W: Prospective evaluation of the role of quantitative Doppler ultrasound surveillance in liver transplantation. Liver Transpl 2004, 10:1183-1188

12. Pompili M, Rapaccini GL, De Luca F, Agnes S, Avolio AW, Covino M, Trombino C, Castagneto M, Gasbarrini G: Doppler ultrasonographic evaluation of the early changes in renal resistive index in cirrhotic patients undergoing liver transplantation. J Ultrasound Med 1999, 18:497-502.

13. Corradi F, Brusasco C, Vezzani A, Palermo S, Altomonte F, Moscatelli P, Pelosi P: Hemorrhagic shock in polytrauma patients: early detection with renal Doppler resistive index measurements. Radiology 2011, 260:112-118.

14. Götzberger M, Kaiser C, Landauer N, Dieterle C, Heldwein W, Schiemann U: Intrarenal resistance index for the assessment of early renal function impairment in patients with liver cirrhosis. Eur J Med Res 2008, 13:383-387.
15. Darmon M, Schortgen F, Vargas F, Liazydi A, Schlemmer B, Brun-Buisson C, Brochard L: Diagnostic accuracy of Doppler renal resistive index for reversibility of acute kidney injury in critically ill patients. Intensive Care Med 2011, 37:68-76.

16. Kirkpatrick AW, Colistro R, Laupland KB, Fox DL, Konkin DE, Kock V, Mayo JR, Nicolaou S: Renal arterial resistive index response to intraabdominal hypertension in a porcine model. Crit Care Med 2007, 35:207-213.

17. Aschwanden M, Mayr M, Imfeld S, Steiger J, Jaeger KA, Thalhammer C: Rapid adaptation of the intrarenal resistance index after living donor kidney transplantation. Nephrol Dial Transplant 2009, 24:1331-1334.

18. Ling Q, Xu X, Li JJ, Chen J, Shen JW, Zheng SS: Alternative definition of acute kidney injury following liver transplantation: Based on serum creatinine and Cystatin C levels. Transplant Proc 2007, 39:3257-3260.

19. Orlando R, Mussap M, Plebani M, Piccoli P, De Martin S, Floreani M, Padrini R, Palatini P: Diagnostic value of plasma cystatin $\mathrm{C}$ as a glomerular filtration marker in decompensated liver cirrhosis. Clin Chem 2002. 48:850-858.

20. Song S, Meyer M, Türk TR, Wilde B, Feldkamp T, Assert R, Wu K, Kribben A, Witzke O: Serum cystatin $C$ in mouse models: a reliable and precise marker for renal function and superior to serum creatinine. Nephrol Dial Transplant 2009, 24:1157-1161.

21. Parikh CR, Devarajan P: New biomarkers of acute kidney injury. Crit Care Med 2008, 36:S159-S165.

22. Mori K, Nakao K: Neutrophil gelatinase-associated lipocalin as the realtime indicator of active kidney damage. Kidney Int 2007, 71:967-970.

23. Kamada N, Calne RY: Orthotopic liver transplantation in the rat. Technique using cuff for portal vein anastomosis and biliary drainage. Transplantation 1979, 28:47-50.

24. Thalhammer C, Aschwanden M, Mayr M, Koller M, Steiger J, Jaeger KA: Duplex sonography after living donor kidney transplantation: new insights in the early postoperative phase. Ultraschall Med 2006, 27:141-145.

25. Legrand M, Mik EG, Johannes T, Payen D, Ince C: Renal hypoxia and dysoxia after reperfusion of the ischemic kidney. Mol Med 2008, 14:502-516.

26. Platt JF, Marn CS, Baliga PK, Ellis JH, Rubin JM, Merion RM: Renal dysfunction in hepatic disease: early identification with renal duplex Doppler US in patients who undergo liver transplantation. Radiology 1992, 183:801-806.

27. Kon V, Sugiura M, Inagami T, Harvie BR, Ichikawa I, Hoover RL: Role of endothelin in cyclosporine-induced glomerular dysfunction. Kidney Int 1990, 37:1487-1491.

28. Akgul A, Ibis A, Sezer S, Basaran C, Usluogullari A, Ozdemir FN, Arat Z, Haberal M: Early assessment of renal resistance index and long-term renal function in renal transplant recipients. Ren Fail 2009, 31:18-24.

29. Kong HY, Zhu SM, Wang LQ, He Y, Xie HY, Zheng SS: Sevoflurane protects against acute kidney injury in a small-size liver transplantation model. Am J Nephrol 2010, 32:347-355.

30. Bellamy MC, Galley HF, Webster NR: Changes in inflammatory mediators during orthotopic liver transplantation. Br J Anaesth 1997, 79:338-341.

31. Bezinover D, Kadry Z, McCullough P, McQuillan PM, Uemura T, Welker K, Mastro AM, Janicki PK: Release of cytokines and hemodynamic instability during the reperfusion of a liver graft. Liver Transpl 2011, 17:324-330.

32. Koelzow H, Gedney JA, Baumann J, Snook NJ, Bellamy MC: The effect of methylene blue on the hemodynamic changes during ischemia reperfusion injury in orthotopic liver transplantation. Anesth Analg 2002, 94:824-829.

33. Hetz H, Bauer M, Lahner D, Faybik P, Winning J, Ankersmit HJ, Bacher A, Krenn CG: Endothelin activation and postoperative renal failure after human liver transplantation. Liver Transp/ 2005, 11:1201-1206.

34. Zarich S, Fang LS, Diamond JR: Fractional excretion of sodium. Exceptions to its diagnostic value. Arch Int Med 1985, 145:108-112.

35. Carvounis $C P$, Nisar $S$, Guro-Razuman S: Significance of the fractional excretion of urea in the differential diagnosis of acute renal failure. Kidney Int 2002, 62:2223-2229.

36. Umgelter A, Reindl W, Franzen M, Lenhardt C, Huber W, Schmid RM: Renal resistive index and renal function before and after paracentesis in patients with hepatorenal syndrome and tense ascites. Intensive Care Med 2009, 35:152-156.

37. Wang J, Du Z, Zhang W, Han B, Peng C, Chen N: Post liver transplantation acute kidney injury in a rat model of syngeneic orthotopic liver transplantation. Lab Invest 2011, 91:1158-1169. 
38. Le Dorze $M$, Legrand $M$, Payen $D$, Ince $C$ : The role of the microcirculation in acute kidney injury. Curr Opin Crit Care 2009, 15:503-508.

39. Park Y, Hirose R, Dang K, Xu F, Behrends M, Tan V, Roberts JP, Niemann CU: Increased severity of renal ischemia reperfusion injury with venous clamping compared to arterial clamping in a rat model. Surgery 2008, 143:243-251.

40. Benes J, Chvojka J, Sykora R, Radej J, Krouzecky A, Novak I, Matejovic M: Searching for mechanisms that matter in early septic acute kidney injury: an experimental study. Crit Care 2011, 15:R256.

doi:10.1186/1471-2369-14-55

Cite this article as: Kong et al:: Intrarenal resistance index for the assessment of acute renal injury in a rat liver transplantation model. BMC Nephrology 2013 14:55.

\section{Submit your next manuscript to BioMed Central and take full advantage of:}

- Convenient online submission

- Thorough peer review

- No space constraints or color figure charges

- Immediate publication on acceptance

- Inclusion in PubMed, CAS, Scopus and Google Scholar

- Research which is freely available for redistribution 